\title{
Milrinone in the treatment of Persistent Pulmonary Hypertension of the Newborn: A Case Series
}

\author{
Norbert Dera $^{1}$, Lukasz Osinski ${ }^{1}$, Piotr Jurkowski ${ }^{2}$, Anna Doboszynska ${ }^{2}$, Slawomir Szajda ${ }^{2}$, \\ and Alina Minarowska ${ }^{2}$ \\ ${ }^{1}$ Regional Specialist Hospital in Olsztyn \\ ${ }^{2}$ University of Warmia and Mazury in Olsztyn School of Medicine
}

February 4, 2021

\begin{abstract}
Persistent Pulmonary Hypertension of the Newborn (PPHN) is defined as a failure of the normal circulatory transition after birth. PPHN manifests as a progressive and potentially fatal hypoxemic respiratory failure. The condition is associated with a persistent increase in pulmonary vascular resistance and reduced blood flow in the pulmonary vessels without an accompanying congenital heart defect. The abnormalities in pulmonary circulation lead to right-to-left shunting through the foramen ovale and usually also through the ductus arteriosus, with resultant hypoxemia, which manifests clinically as cyanosis. Management options in PPHN include optimal lung inflation, oxygenation, prevention of acidosis, stabilization of blood pressure, sedation and pulmonary vasodilator therapy. While inhaled nitric oxide (iNO) is the most commonly used treatment option, alternative methods can be used whenever is unavailable or contraindicated. We report three cases of severe PPHN, in which due to the lack of adequate response to intravenous $\mathrm{MgSO} 4$, the patients were switched to milrinone.
\end{abstract}

\section{Introduction}

Persistent pulmonary hypertension of the newborn (PPHN) is a clinical syndrome characterized by the presence of respiratory failure and hypoxia. PPHN develops if pulmonary vascular resistance exceeds the systemic vascular resistance for a prolonged time after birth. This leads to right-to-left shunting of hypooxygenated blood through the foramen ovale (F.o.) and, in most cases also through persistent ductus arteriosus (DA) [1]. A consequence of this is severe hypoxemia associated with the presence of a substantial proportion of hypo-oxygenated venous blood in the systemic circulation [2].

The prevalence of PPHN is estimated at 0.4-6.8 Although PPHN is observed primarily in full-term neonates or those delivered nearly at term, it may also be diagnosed in some preterm newborns with respiratory disorders and bronchopulmonary dysplasia. Typically, PPHN develops secondary to delayed or impaired pulmonary vascular relaxation, associated with various lung pathologies [4]. The causes of PPHN can be classified into the four groups: 1) developmental malformations (pulmonary hypoplasia, congenital diaphragmatic hernia, Potter syndrome, alveolar capillary dysplasia), 2) anatomical changes in pulmonary vessels (chronic intrauterine hypoxia, salicylate ingestion in pregnancy, smoking in pregnancy), 3) pulmonary vasoconstriction (congenital pneumonia, meconium aspiration syndrome, severe perinatal hypoxia, sepsis, respiratory distress syndrome), and 4) disorders of the pulmonary circulation (pulmonary embolism, polycythemia) [5].

Currently, the gold standard in the management of PPHN is inhaled nitric oxide (iNO), and the most advanced treatment option is extracorporeal membrane oxygenation (ECMO). However, in line with the proposed Polish standards of PPHN management, alternative treatment modalities can be used whenever iNO therapy is unavailable or contraindicated [6]. Contraindications to iNO therapy include intraventricular 
hemorrhage (IVH, more than grade 2), severe disorders of hemostasis (unless compensated), $>5 \%$ methemoglobinemia and deficiency of hemoglobin reductase. The iNO product available in Poland has not been authorized for the use in neonates born before 34 weeks of gestation [7]. The list of proposed alternative treatment modalities includes magnesium sulfate, milrinone and sildenafil.

In this paper, we review three cases of severe PPHN, all initially treated with magnesium sulfate. Given the lack of adequate treatment response, the patients were switched to milrinone (Corotrope), administered according to the product dossier. The severity of respiratory failure was estimated based on oxygen saturation index (OSI) which despite being less invasive measure than oxygenation index (OI) (contrary to OI, determination of OSI does not require arterial access) was shown to correlate well with the latter (OI [?] 2 $\times$ OSI) [8-10].

\section{Case Reports}

Clinical characteristics of the cases are summarized in Table 1, and distributions of cardiorespiratory parameters before administration of milrinone and 12-36 hours thereafter are shown in Table 2.

Case 1

A male neonate from the first pregnancy complicated with gestational hypertension and premature rupture of membranes (amniotic fluid release 23 hours before labor) was delivered vaginally at 35 weeks of gestation, with a birth weight of $2530 \mathrm{~g}$. The neonate was diagnosed with pulmonary hypertension associated with RDS and congenital pneumonia.

The signs of progressive respiratory failure have been observed starting at $10 \mathrm{~min}$ after birth. The changes observed in lung ultrasonography corresponded to grade 1 respiratory distress syndrome (RDS). Echocardiography demonstrated bilateral flow through the DA, along with tricuspid regurgitation. Laboratory tests revealed elevated levels of inflammatory markers. Empirical combination antibiotic therapy with ampicillin and gentamycin was started, along with the infusion of 20\% magnesium sulfate (4-12 hours of age) and surfactant (Curosurf). Given the lack of an adequate clinical response and echocardiographic evidence of progressive PPHN, a loading dose of milrinone has been administered $(25 \mu \mathrm{g} / \mathrm{kg}$ for $15 \mathrm{~min}$, followed by $0.5 \mu \mathrm{g} / \mathrm{kg} / \mathrm{min}$ ). Due to a short-term decrease in arterial pressure, the dose of milrinone was tapered down to $0.25 \mu \mathrm{g} / \mathrm{kg} / \mathrm{min}$. Considering a deterioration of echocardiographic indices after an attempt to withdraw milrinone at approximately 35 hours of the treatment (as recommended by the manufacturer), a decision to continue the therapy for a total of 62 hours has been made. The treatment eventually contributed to the improvement of the echocardiographic indices (reversion of flow through the DA and regression of tricuspid regurgitation) and a substantial decrease in the respiratory effort so that the patient could be extubated at approximately 84 hours of age. Neither disorders of hemostasis nor echoencephalographic abnormalities were observed throughout the treatment.

\section{Case 2}

A male neonate from the fifth pregnancy (third labor) complicated with anemia and hypothyroidism was delivered at 41 weeks of gestation with a birth weight of $4120 \mathrm{~g}$. The neonate presented with meconium aspiration syndrome (MAS) and the signs of congenital infection. Moreover, the signs of progressive respiratory failure and an evident increase in the levels of inflammatory markers have been observed beginning at birth. A combined empirical antibiotic therapy with ampicillin and gentamycin was started, and at approximately 4 hours of age, the neonate was intubated and administered surfactant (Curosurf). Despite this, the patient's condition remained severe, and laboratory evidence of hypoxemia emerged (oxygen saturation 80-85\% despite $100 \% \mathrm{fiO}_{2}$ ). Given the suspicion of progressive PPHN, an infusion of $20 \%$ magnesium sulfate was started, but without a satisfactory therapeutic effect. Echocardiography showed left-to-right flow through the F.o., right-to-left shunting in the DA and mild tricuspid regurgitation. Administration of milrinone at approximately 10 hours of age (loading dose of $50 \mu \mathrm{g} / \mathrm{kg}$, followed by $0.5 \mu \mathrm{g} / \mathrm{kg} / \mathrm{min}$ ) contributed to a rapid increase in oxygen saturation so that the ventilation parameters could be reduced. Echocardiography demonstrated predominantly left-to-right flow in the DA and F.o. Milrinone was withdrawn after achieving a 
satisfactory therapeutic effect at approximately 27 hours of the treatment. However, the patient's condition has deteriorated rapidly approximately three hours later, requiring modification of the pressor amine doses, re-introduction of milrinone at continuous infusion $(0.75 \mu \mathrm{g} / \mathrm{kg} / \mathrm{min})$, administration of $20 \%$ magnesium sulfate $(200 \mathrm{mg} / \mathrm{kg}$ in bolus) and transfer to another center where iNO therapy was available. Following the transfer, the neonate remained under mechanical ventilation, received $20 \% \mathrm{MgSO}_{4}$ and pressor amines, along with vancomycin and cefuroxime as MRCNS strain of S. epidermidis was isolated from the lower respiratory tract. The treatment contributed to a gradual improvement of the patient's condition. At approximately ten days of age, the neonate could be extubated, and oxygen therapy was no longer needed starting on day 12. No abnormalities were found on control echoencephalography carried out before the discharge.

\section{Case 3}

A female neonate from the fourth pregnancy complicated by the presence of placenta previa and anemia was delivered via cesarean at 23.5 weeks of gestation because of placental abruption. The neonate, with a birth weight of $820 \mathrm{~g}$, was in severe condition, with the signs of extreme prematurity and progressive respiratory failure. Surfactant (Curosurf, two doses: $200 \mathrm{mg} / \mathrm{kg}$ and $100 \mathrm{mg} / \mathrm{kg}$, respectively) was administered on the first day of age, and mechanical ventilation with gradually increased parameters was implemented, along with combined empirical antibiotic therapy with ampicillin and gentamycin. Because of severe hyperglycemia, the neonate received insulin on days 1 to 6 . Echocardiography performed at approximately 20 hours of age showed tricuspid regurgitation with velocity up to $3 \mathrm{~m} / \mathrm{s}$, mitral regurgitation, reduced myocardial contractility, and a wide DA with right-to-left shunting. The changes found on chest ultrasonography corresponded to the grade 2 RDS. At approximately 21 hours of age, the patient was administered $20 \%$ magnesium sulfate $(200 \mathrm{mg} / \mathrm{kg})$. Given the lack of improvement, intravenous Milrinone $(50 \mu \mathrm{g} / \mathrm{kg}$ for 1 hour, followed by 0.5 $\mu \mathrm{g} / \mathrm{kg} / \mathrm{min}$ for 2 hours in a continuous infusion, and $0.25 \mu \mathrm{g} / \mathrm{kg} / \mathrm{min}$ for another 32 hours) has been implemented starting at approximately 23 hours of age. Furthermore, pressor amines, dobutamine and dopamine, were administered to control hypotension (MBP $20 \mathrm{mmHg}$ ) and to improve myocardial contractility. The treatment contributed to the improvement of cardiorespiratory parameters (normalization of oxygen saturation, reduction of oxygen demand, decrease in respiratory effort). The echocardiographic examination demonstrated improvement of myocardial contractility, a decrease in tricuspid regurgitation velocity down to $2.25 \mathrm{~m} / \mathrm{s}$, a mild mitral regurgitation and bilateral flow in the DA. Despite these improvements, the patient's condition remained critical. Echoencephalography carried out on subsequent days showed bilateral hemorrhage, grade 4 (periventricular hemorrhagic infarction, PVHI) according to the modified Papile grading system. Echocardiography revealed hemodynamically relevant left-to-right flow in the DA, which persisted despite an attempt of pharmacological ligation with intravenous paracetamol and furosemide on days 3-5. As the signs of coagulation disorders emerged on days 2 and 3, the patient received vitamin $\mathrm{K}$ and fresh frozen plasma. On day 5, the neonate received an additional transfusion of irradiated leukocyte-depleted erythrocyte concentrate because of progressive hypoxemia. Despite intensive therapy, the general condition of the patient continued to deteriorate and was eventually classified as terminal. The neonate died at six days of age due to multiorgan failure associated with extreme prematurity.

\section{Discussion}

The mechanisms of action and targets of pulmonary vasodilators differ from agent to agent, and hence, various therapeutic variants can be used depending on specific product availability and experience of a given center.

Magnesium sulfate is a natural blocker of calcium channels, one of the most common agents administered to patients with PPHN. Despite multiple documented good experiences with magnesium sulfate, a metaanalysis of clinical trials published in 2007 did not provide enough evidence to recommend the administration of this agent in patients with PPHN [11]. However, the results of further studies seem to be promising [12]. Aside from vasodilation, magnesium sulfate has also a strong sedative effect when administered at higher doses, and hence, additional sedation is not needed or can be limited. Although none of the patients included in this case series responded adequately to the magnesium sulfate therapy, this agent has been successfully used in other patients treated at our center. Another important argument for the use of magnesium sulfate 
is the lack of significant side effects as long as the concentration of magnesium is maintained within the recommended range; the side effects were also not observed in any of the patients included in this series.

Milrinone is a phosphodiesterase 3 (PDE3) inhibitor. This agent is frequently used at cardiology departments because of its inotropic and vasodilatory effects. Its vasodilating effect in pulmonary vessels was first documented in an experimental study of ovine fetuses [7]. Milrinone was also shown to produce beneficial effects when combined with inhaled nitric oxide in neonates who did not respond adequately to iNO monotherapy [8-10]. Milrinone can be particularly useful in patients in whom PPHN coexists with left ventricular dysfunction [13].

According to literature, potential adverse effects of Milrinone therapy include increased risk of IVH and hypotension [14]. While electroencephalography showed no cerebral abnormalities in cases 1 and 2 included in our series, a massive bilateral PVHI was observed in case 3. However, this complication should not be linked solely to the use of milrinone and seemed to be primarily related to extreme prematurity of the patient, resultant multiorgan failure and dysfunction of regulatory mechanisms.

In cases 1 and 3, a decrease in mean arterial pressure was observed after milrinone administration. Mean arterial pressure normalized after the milrinone dose has been tapered down to $0.25 \mu \mathrm{g} / \mathrm{kg} / \mathrm{min}$, still sufficient to maintain the therapeutic effect. While administration of pressor amines was not required in case 1 , combination therapy with dobutamine and dopamine had to be given in case 3, given extreme prematurity of the patient, cardiorespiratory failure, and a slight a decrease in systemic blood pressure. In case 2, administration of dobutamine, later combined with dopamine, was required due to disorders of systemic blood pressure that emerged during the administration of $20 \% \mathrm{MgSO}_{4}$, before the introduction of milrinone.

Noticeably, an early attempt to withdraw milrinone in cases 1 and 2 was reflected by the worsening of the general condition of the patients and their echocardiographic parameters. This might justify prolonged administration of the agent, perhaps longer than the 35 hours recommended by the manufacturer [15], even despite an evident therapeutic effect. While our patients showed good tolerance to prolonged milrinone therapy, this issue requires further verification.

In all hereby presented cases, the administration of milrinone was associated with a favorable clinical effect, namely a regression of clinical manifestations of PPHN and related echocardiographic anomalies.

To summarize, milrinone can be an effective treatment option in PPHN and may constitute an alternative for the recommended, albeit not always available or contraindicated therapies. Importantly, we did not observe an evident unfavorable relationship between the drug tolerance and its dose and treatment duration; furthermore, none of our patients showed signs of clinically significant hypotension. Milrinone seems to have a similar effect on fluctuations of systemic blood pressure as $20 \% \mathrm{MgSO}_{4}$, and its therapeutic effect is similar or stronger than in the case of the latter agent.

\section{References}

[1] Kopeć G., Kurzyna M., Mroczek E. et al. Characterization of Patients with Pulmonary Arterial Hypertension: Data from the Polish Registry of Pulmonary Hypertension (BNP-PL). J Clin Med. 2020 Jan 8;9(1). pii: E173. [2] Siennicka A., Darocha S., Banaszkiewicz M. et al. Treatment of chronic thromboembolic pulmonary hypertension in a multidisciplinary team. Ther Adv Respir Dis. 2019 Jan-Dec;13:1753466619891529. [3] Travadi JN, Patole SK: Phosphodiesterase inhibitors for persistent pulmonary hypertension of the newborn: A review. Pediatr Pulmonol 2003; 36: 529-535. [4] Nair J, Lakshminrusimha S, Update on PPHN: mechanisms and treatment. Semin Perinatol. 2014 Mar;38(2):78-91. doi: 10.1053/j.semperi.2013.11.004. [5] Zalecenia Polskiego Towarzystwa Neonatologicznego. Standardy opieki medycznej nad noworodkiem w Polsce. Wydanie II (2017), zaktualizowane i uzupełnione. [Recommendations of the Polish Society of Neonatology. Standards of medical care for neonates in Poland. Second edition (2017), revised and updated.] Warsaw, PTN\&Media-Press Sp. z o.o. 2017, 171-176 [6] Medicinal product dossier: INOmax, INN-nitric oxide [7] Lakshminrusimha S, Porta NF, Farrow KN, Chen B, Gugino SF, Kumar VH, et al. Milrinone enhances relaxation to prostacyclin and iloprost in pulmonary arteries isolated from lambs with persistent pulmonary 
hypertension of the newborn. Pediatric critical care medicine: a journal of the Society of Critical Care Medicine and the World Federation of Pediatric Intensive and Critical Care Societies. 2009;10:106-12. [8] Walas W, Borszewska- Kornacka M, Świetliński J - Zespół przetrwałego nadciśnienia płucnego u noworodków. Algorytm leczenia. [Persisten pulmonary hypertension of the newborn. A therapeutic algorithm.] MediPage, 2012,11-14 [9] Rawat M., Chandrasekharan P.K., Williams A., Gugino S., Koenigsknecht C., Swartz D., Ma C.X., Mathew B., Nair J., Lakshminrusimha S. Oxygen saturation index and severity of hypoxic respiratory failure. Neonatology. 2015;107:161-166. [7] Khemani RG1, Thomas NJ, Venkatachalam V, Scimeme JP, Berutti T, Schneider JB, Ross PA, Willson DF, Hall MW, Newth CJ; Comparison of SpO2 to PaO2 based markers of lung disease severity for children with acute lung injury. Pediatric Acute Lung Injury and Sepsis Network Investigators (PALISI). Crit Care Med. 2012 Apr;40(4):1309-16. [8] McNamara PJ, Shivananda SP, Sahni M, Freeman D, Taddio A. Pharmacology of milrinone in neonates with persistent pulmonary hypertension of the newborn and suboptimal response to inhaled nitric oxide. Pediatric critical care medicine: a journal of the Society of Critical Care Medicine and the World Federation of Pediatric Intensive and Critical Care Societies. 2013;14:74-84. [9] Bassler D, Choong K, McNamara P, Kirpalani H. Neonatal persistent pulmonary hypertension treated with milrinone: four case reports. Biol Neonate. 2006;89:1-5. [10] McNamara PJ, Laique F, Muang-In S, Whyte HE. Milrinone improves oxygenation in neonates with severe persistent pulmonary hypertension of the newborn. J Crit Care. 2006;21:217-22 [11] Ho J.J., Rasa G.: Magnesium sulfate for persistent pulmonary hypertension of the newborn. Cochrane Database Syst Rev 2007, 18:CD005588. [12] Boo N.Y., Rohana J., Yong S.C. et al.: Inhaled nitric oxide and intravenous magnesium sulphate for the treatment of persistent pulmonary hypertension of the newborn. Singapore Med J 2010, 51:144-150. [13] SatyanLakshminrusimhaMDBobbyMathewMRCPCorinne L.LeachMD, PhD Seminars in Perinatology Volume 40, Issue 3, April 2016, Pages 160-173 [14] Bassler D, Choong K, McNamara PJ, Kirpalani H. Neonatal persistent pulmonary hypertension treated with milrinone: four case reports. Biol Neonate 2006; 89: 1-5. [15] Medicinal product dossier: Corotrope

\section{Hosted file}

Table 1.pdf available at https://authorea.com/users/393611/articles/507203-milrinone-in-thetreatment-of-persistent-pulmonary-hypertension-of-the-newborn-a-case-series

\section{Hosted file}

Table 2.pdf available at https://authorea.com/users/393611/articles/507203-milrinone-in-thetreatment-of-persistent-pulmonary-hypertension-of-the-newborn-a-case-series 